\title{
L'espiritualitat de sant Vicent Ferrer en el context de la seua època
}

\author{
Spirituality of saint Vincent Ferrer in his age's context
}

\author{
Miguel NAVARro Sorní \\ navarrosorni@telefonica.net
}

Facultat de Teologia de València

Resum: L'objectiu de l'article és situar l'espiritualitat de sant Vicent Ferrer en el context crític de la seua época, i mostrar com eaquell context condiciona la major part de les característiques de la seua espiritualitat, que té en la predicació de l'Evangeli el seu tret més característic i que aglutina tota la seua vida i la seua doctrina.

Paraules clau: espiritualitat tardomedieval, sant Vicent Ferrer, context històric.

\begin{abstract}
The aim of this article is to analyze the spirituality of Saint Vicent Ferrer within the crisis context of his time, and to show how this context influenced most properties of his spirituality; particulary, as his most relevant characteristic, his evangelic preaching, which summarizes his life and doctrine.
\end{abstract}

Keywords: late medieval spirituality, saint Vincent Ferrer, historical context. 
L'objectiu del present treball no és exposar de manera sistemàtica l'espiritualitat de sant Vicent Ferrer, tema sobre el qual comptem amb algunes publicacions (no moltes, per cert, menys de les que cabria desitjar $)^{1}$ sinó més aïna comprendre-la i comprendre la figura del sant en el context de la seua època, perquè si això és necessari a l'hora d'estudiar qualsevol idea o personatge històric, ho és encara més en el seu cas, perquè la imatge que tenim de sant Vicent (i això afecta a la seua espiritualitat) és una mescla de realitat històrica i d'imaginació popular (de llegenda), i una imaginació popular tan desbordada que arriba a distorsionar la vertadera fesomia històrica del personatge i les seues idees. Així, la visió popular que d'ell es té (almenys a València) és, abans que res, la d'un miracler, un taumaturg peculiar, i també la d'un frare dur, sever, que estén iradament el seu dit índex al cel anunciant desgràcies, mentre amenaça als seus oients amb la còlera divina. Certament aquelles visions de sant Vicent corresponen a la realitat, però parcialment, és a dir expressen només una part, un aspecte de la seua portentosa i complexa figura i, a més, tenen l'inconvenient que han contribuit a ocultar, o almenys a relegar a segon pla, el tret principal del sant i de la seua espiritualitat: la seua dimensió apostòlica, de predicador de l'evangeli.

En efecte, la predicació de l'evangeli és la clau de comprensió de la figura de sant Vicent Ferrer i de la seua espiritualitat, la perspectiva que permet aglutinar tota la seua vida i doctrina, alhora que conferix a ambdós una gran actualitat en el context eclesial d'un moment històric en què es parla d'una nova evangelització, és a dir de tornar a anunciar l'evangeli a les gents que sent cristianes han perdut la fe o se n'han oblidat d'ella. I això és el que va fer sant Vicent Ferrer en el seu temps i l'objectiu a què es dirigia tant la seua predicació com l'espiritualitat que n'estava en la base. Va ser i va voler ser, abans que res, un predicador de l'evangeli (per això va ingressar en l'Orde de Predicadors); un predicador a l'estil del seu temps, certament, amb les categories i modes de la seua època, tan diferents dels nostres, i per això sovint difícils de comprendre. I des d'una perspectiva apostòlica hem de presentar la seua imatge i la seua espiritualitat, si volem comprendreles correctament.

\section{Les repercussions espirituals d'un temps de crisi}

Com és sabut, Vicent Ferrer va nàixer a València, el 23 gener 1350, en el carrer del Mar, fill del notari Guillem Ferrer i de la seua esposa Constanza Miquel; pertanyia, per tant, a eixa «burgesia» urbana emergent, feta del que hui anomenaríem «professionals liberals» (advocats, notaris, metges), i de mercaders, oficials públics i amos de tallers (xicotets empresaris, diríem hui), que estava canviant la faç de les ciutats d'Europa amb un aire nou i actiu. Seixanta-nou anys després, morirà a la ciutat de Vannes (a la Bretanya francesa) el 5 d'abril de 1419, en una terra assolada per la guerra i diverses calamitats.

1 Entre elles podem citar la segona part de la «Introducción a la obra literaria de san Vicente», amb el títol: «Teología del apostolado según san Vicente», realitzada pels pares dominics José María de Garganta i Vicente Forcada, dins de la seua obra Biografía y escritos de San Vicente Ferrer, Madrid 1956, pp. 364-399. També: Esponera Cerdán (2007) i Baloup (2008). 
La seua vida, per tant, transcorre en la segona mitat del segle XIV i els inicis del XV, un temps que l'historiador holandés Johan Huizinga va definir com «la tardor de l'Edat Mitjana», ${ }^{2}$ perquè el món medieval agonitzava deixant pas al modern. Va ser un temps de crisi, a tots els nivells: moral, social, polític, econòmic, cultural, i sobretot religiós, en el cos eclesial a causa del Cisma d'Occident.

En efecte, el segle XIV a Occident es troba marcat pel signe de la crisi. Crisi demogràfica, a causa de diversos factors, com les sequeres, les males collites, les caresties i fams canines que se succeïxen dramàticament $\mathrm{i}$ afavoreixen l'aparició de malalties endèmiques i epidèmies de pesta, que es fan habituals a Occident a partir de 1347. A açò cal afegir la generalització de la guerra, que de conflictes feudals localitzats es transforma en enfrontaments entre estats (perquè en aquell moment estan sorgint les nacionalitats), com la més característica i devastadora: la Guerra dels Cent Anys, que de mitjans del segle XIV a mitjans del XV enfrontarà França i Anglaterra, i comportarà tot un seguici de misèries i morts.

Aquella crisi va ser seguida d'una altra en el pla social i econòmic, que erosionarà el model feudal de societat, $i$ originarà un conjunt de transformacions en la societat europea, a costa de greus convulsions socials, sobretot en el medi rural que coneixerà violents alçaments de llauradors contra els senyors, però també en l'urbà, on els ciutadans «mitjans» se sublevaran contra un patriciat que amb la seua hegemonia econòmica els tancava el pas al poder polític.

Doncs bé, tot açò va tindre fondes repercussions espirituals, amb la conseqüència que es produeix un decaïment espiritual general, es difon un cert pessimisme ${ }^{3}$ i els esperits més sensibles busquen certeses interiors de salvació, vies d'accés personal a la divinitat que asseguren l'alliberament de les culpes i la salvació, perquè la institució eclesial està molt qüestionada, els ordes conventuals i mendicants decaiguts i el clero secular desprestigiat. Els grans ideals teòrics dels escolàstics del segle XIII han quedat lluny, les grans construccions metafísiques i teològiques, com La Suma Teològica de sant Tomàs d'Aquino, i la mística especulativa a què van donar origen, són objecte de la crítica nominalista, perquè fan la impressió de ser il lusòries i merament verbals, simples construccions ideals, sense base real.

En contacte amb un nou ambient sociocultural, la teologia i l'espiritualitat cristianes assumeixen ara accents diversos de què tenien en els segles precedents; s'aparten de l'optimisme racional que

\footnotetext{
2 Johan Huizinga, El otoño de la Edad Media. Estudio sobre las formas de la vida y del espiritu durante los siglos XIV y XV en Francia y en los Países Bajos. Publicada en holandés l'any 1919, es va traduir a l'espanyol per primera vegada en 1929, en l'editorial Revista de Occidente. Posteriorment ha conegut nombroses edicions en diverses editorials.

3 Respecte d'això, escriu Johan Huizinga que en aquell temps: «fuera de la esfera del arte reina por todas partes la oscuridad. En las amenazadoras advertencias de los predicadores, en el cansado suspirar de la literatura, en la monótona información de las crónicas y de los documentos, se percibe el grito de los pecados saturados de color y el lamento de la miseria. [...] Es un mundo malo. El fuego del odio y la violencia se eleva en altas llamaradas. La injusticia es poderosa, el diablo cubre con sus negras alas una tierra lúgubre, y la humanidad espera para en breve el término de todas las cosas» (Huizinga 1971: 42-43 i 49).
} 
havia dominat la teologia de sant Anselm a sant Tomàs d'Aquino, per a prendre novament antics tons monàstics de pessimisme i de fideisme, de moralisme i de concreció empírica, pràctica que condueixen, en el cas de l'espiritualitat, per un costat a posar l'atenció en les seues manifestacions psicològiques, com visions i revelacions, que comencen a ocupar un lloc privilegiat en l'horitzó espiritual de l'època, tal com es percep en els casos de Juliana de Norwich (+ c. 1442) o Margery Kempe (+ 1440), alhora que, d'altra banda, es percep com l'espiritualitat s'aparta de la mística especulativa (perquè pareix suggerir que el ser humà a través dels seus exercicis de contemplació pot arribar a la visió de Déu), per a centrar-se en l'essencial de l'evangeli: la pràctica de l'amor, alimentada en la meditació de la humanitat i la passió de Crist, que passa a convertir-se en la medul la d'una vida espiritual simplificada, accessible a tots, sense necessitat de retirar-se a un claustre per a aconseguir-la i viure-la (cf. Vandenbroucke 1961; Leppin 2010; Mezzadri 2001: 247288).

Com veiem, es donen aspectes diversos, inclús antagònics, per la qual cosa els estudiosos de l'espiritualitat d'aquell moment històric ens adverteixen que es tracta d'una espiritualitat heterogènia, en la que es donen cita factors sovint oposats o almenys diversos, distints; una espiritualitat que només podem descriure amb una multiplicitat de pols, on trobem tendències exteriorizants, d'una banda, que s'oposen a tendències interiorizants, per una altra; on, d'una banda, observem una inclinació a concebre la relació amb Déu en esquemes graduals, metòdics; i d'altra la busca d'una relació directa amb Déu per la gràcia. Per tant, no hem d'estranyar-nos si en el mateix sant Vicent Ferrer trobem la presència d'elements espirituals divergents, uns amb trets de pietat clarament medieval i altres; no obstant això, ja en la línia de la devotio moderna.

Del que s'ha dit s'infereix que la crisi del pas del segle XIV al XV no pot identificar-se sense més amb una decadència espiritual, com tantes vegades s'ha dit, perquè la mateixa crisi que condueix a una clara decadència és també esperó i estímul per a una renovació, per la qual cosa seria simplista tancar l'espiritualitat de l'època davall el denominador exclusiu del declivi espiritual, insistint en els tan repetits aspectes negatius d'aquell moment (aseglarament o mundanització del clergat, laxitud dels ordes religiosos, ignorància religiosa del poble, extensió de vicis i supersticions, etc.), aspectes que són certs, sens dubte, però no els únics, perquè van parells amb grans mostres externes de fervor - de fet, Francesc Eiximenis lloa el poble valencià per la seua religiositat, com a «poble be aveat a seguir l'ofici eclesiàstic e sermons, e a festivar e a solemnitzar qualsevol cosa quan es deu fer», i insta els regidors públics de València a «fer bells oficis e grans profesons e solemnitats» (Eiximenis 1983 : 301 i 293)-, així com amb una major difusió de la Bíblia, i amb la recerca d'experiències espirituals més sinceres, més íntimes, més profundes, més evangèliques.

Ara bé, podem aventurar sense por d'equivocar-nos que el factor dominant de la vida espiritual de l'època, i de sant Vicent, va ser la consciència de la fi del món, perquè els contemporanis del sant estaven convençuts de que la fi estava prop, no sols en el sentit de la fi individual, personal, amb la mort, sinó en el sentit de la fi del món, el final col lectiu. La gran pesta que de 1347 a 1351 va assolar 
àmplies regions d'Europa, va fer viure de prop aquella experiència. I el fet va ser interpretat com un castic diví, que cridava a la penitència, com ho mostren les innombrables processons de flagel lants que es van difondre per tot Europa. Aquell era el clima espiritual en què sant Vicent ve al món.

La idea de la pròxima fi del món, de la desaparició col lectiva, va conferir un dramatisme major inclús al fet de la mort individual. I és ara quan es difonen en major grau les representacions pictòriques de la «dansa de la mort», $i$ apareixen les artes moriendi, on s'ensenya l'art de preparar-se a bé morir, i es pot afirmar que en cap època la idea de la mort ha tingut una rellevància tan intensa com en la segona mitat del segle XIV i els inicis del XV.

Així ho mostra també el fet que és en aquell precís moment quan sorgeixen moltes confraries o altres associacions religioses que inclouran entre els seus fins l'ajudar a bé morir els agonitzants, soterrar els ajusticiats o els vagabunds, els cadàvers dels quals no eren reclamats per ningú, assegurant-los un enterrament cristià, construint tombes dignes per a ells (a fi que els seus cadàvers no foren abocats als femers) i arreplegant almoines per a celebrar misses per les seues ànimes, per a aconseguir la seua salvació. Unes confraries que prompte caracteritzaran en mesura creixent la imatge de la religiositat urbana tardomedieval, mantindran viva la memòria de la mort. Pensem en la Confraria dels Innocents de València, que s’inscriu en la mateixa línia.

\section{Sant Vicent Ferrer: una espiritualitat per a un temps crític}

Doncs bé, Vicent Ferrer és fill d'aquell ambient espiritual «enrarit», alhora que portador d'aires nous, perquè la seua València no serà una excepció al clima de crisi general europea. Així, quan Vicente naix la ciutat i el regne es recuperaven dificultosament de la terrible pesta del 1348 i de les guerres de la Unió amb les seues violentes repressions. No va vindre al món en una ciutat pròspera i tranquil la, sinó en uns anys de profundes convulsions. I durant la seua infància i adolescencia coneixerà més desgràcies i catàstrofes en la seua terra: les grans sequeres del 1356 al 1359, repetides alguns anys més tard, que van ocasionar grans fams canines; el rebrot de la pesta bubónica l'any 1362 (coneguda com la mortaldat dels infants, pels molts xiquets víctimes de l'epidèmia), i les desastroses conseqüències de les guerres amb Castella: destrucció de collites i bestiars, carestia de queviures, fam, pobresa, augment de viudes i òrfens, etc.

D'altra banda, en la València de Vicent Ferrer es donaven sagnants bandositats o enfrontaments armats entre famílies nobles per pugnes internes entre elles i pel control del poder, que es van revifar en la década delsanys 70 del segle XIV, i no cessarien fins ben entrat el segle següent. Les bandositats impregnaven la vida valenciana de sentiments d'odi i venjança, que es traduïen en continues lluites, enfrontaments armats i assassinats, que generaven un enorme i profund desorde social (clàssic és l'enfrontament entre els Centelles i els Vilaragut, que degué calmar Vicent Ferrer davant de la impotència de l'autoritat ciutadana i reial per a fer-ho). 
Però el desorde social valencià no es limitava a les bandositats nobiliàries, i el descriu amb amplitud un autor contemporani del nostre sant, Francesc Eximenis, en la carta dedicatòria del seu Regiment de la cosa pública, on adverteix als jurats de València que «com gran part del ditpoble no sia natural [és a dir, són forasters que hi aflueïxen en busca de treball] ne sia per açó molt ric, per tal el fa pitjor regir, car és abans escomogut, e aitant com menys hi ha a perdre és pus dispost a fer avalots». I conclou: «Per totes aquestes coses cové que en esta ciutat haja sovint grans bregues e grans nafres, e sovint morts d'homens, e per consegüent granscrims» (Eiximenis 1983: 293).

Vicent Ferrer viu, doncs, en una València assolada per desgràcies (epidèmies, sequeres, caresties, fam, guerra), una València agressiva, buscabregues, violenta, i al temps superficial, frívola, immoral, com ell mateix denunciarà en els seus sermons, en què critica els vicis del clero i del poble. És fill de la seua època i tots els elements negatius, units a la gran crisi eclesial del Cisma d'Occident, donaran a la seua espiritualitat un to general no de pessimisme -sant Vicent no és en absolut pessimista-, però sí de denúncia, de censura, de crítica, de crida urgent a la conversió, perquè percep en totes aquelles calamitats, sobretot en la divisió eclesial, els signes premonitoris de la pròxima fi del món. I això serà l'eix central de la seua espiritualitat.

Però a Vicent Ferrer no li interessa la fi del món en si mateixa, no l'anuncia a l'estil visionari i turbulent dels spirituali franciscans, sinó que li preocupa que els seus oients estiguen preparats per a quan arribe. El que ell persegueix amb les seues predicacions és la transformació de la vida, la santificació del cristià, la conversió: que els seus oients muiren al pecat i visquen en la fe per a Déu, evitant els vicis i practicant les virtuts, com dirà en un dels seus sermons: «En dos coses consistix la santedat, a saber: en que la criatura buide el seucor de tot allò terrenal i mundà i l'eleve al celestial» (Garganta-Forcada 1956: 376). Ara bé, en el context concret de la seua època Ferrer predica la conversió, un retorn a la vivència de la santedat, com una urgència dramàtica i ineludible, d'ací la vehemència i l'afany que posa en l'exercici de la seua missió, perquè pensa que s'acosta la fi dels temps. La divisió de l'Església, els mals i calamitats que afligeixen al món són per a ell signes certs de l'arribada de la fi del món, del juí final, són les angoixes predites pel Senyor que precedeixen a la fi (cf. Mt 24, Lc 21, 5-36). D'ací que el seu lema o eslogan preferit per a constrényer les gents a la conversió siguen unes paraules del llibre de l'Apocalipsi $(14,6)$, que han passat a formar part de la seua iconografia tradicional i les llegim en la bíblia que porta en la seua mà o en el filacteri que corona el seu cap: «Timete Deum et date illi honorem quia venit iuditium eius» (Temeu Déu i doneu-li glòria, perquè arriba el seu juí).

Així doncs, la predicació apocalíptica de sant Vicent Ferrer s'enquadra en el que Kathryn KerbyFulton ha denominat «reformisme apocalíptic»; és a dir, un ús pedagògic d'aquella temàtica amb vista a la reforma de l'Església o del poble; i en el cas de Ferrer dirigit a la conversió dels seus oients. Com afirma Losada: «Los sermones [vicentinos] del fin del mundo siempre señalan la responsabilidad humana sobre la ira divina y la reforma y conversión auténtica como último recurso de salvación» (2019: 204). Tot en ells està ordenat a «estimular la reforma moral y de costumbres», insistint en la 
imminència de la fi i els terrors i els patiments que portarà per a provocar a l'esmena de vida. I un bon coneixedor del sant, Alfons Esponera, sosté que si el mestre Vicent va predicar la imminència del juí final i la vinguda de l'Anticrist, «siempre lo hizo dentro del planteamiento de la necesidad de reforma de la sociedad cristiana, y sobre todo, de conversión individual» (Esponera 2007: 57).

De fet, per a sant Vicent el fi de l'espiritualitat és exercitar la vida de l'Esperit, la gràcia de la filiació divina, l'amor de Déu (la caritat), que ha sigut infòs en nosaltres pel bautisme, a fi de viure en docilitat a les mocions d'eixe Esperit, l'Esperit Sant, i arribar així a la salvació eterna. Es tracta, per tant, d'un procés ascensional, d'un elevar-se cap a Déu amb l'ajuda de la gràcia i dels mitjans espirituals al nostre abast com l'oració i la penitència, a fi d'ordenar tot allò que és natural cap a l'espiritual i estar cada dia més prop de Déu. Així, dirà en un sermó: «La vida dels bons sempre creix i augmenta $[\ldots]$ perquè les persones justes estan en gràcia de Déu, i quan obren i deliberen -elspensaments del seu cor, les paraules de la seua boca, les obres del cos, inclús les obres naturalstot és meritori [...fins i tot les obres naturals, perquè] mengen i dormen per a millor servir Déu; riuen per a poder plorar. Tot és meritori, tot fa elevar-se cap a Déu. La persona que està en gràcia sempre ascendeix: és millor hui que ahir, i demà millor que hui.» (Garganta-Forcada 1956: 379).

Com veiem, sant Vicent conjuga perfectament, d'una banda, una mística tradicional dominicana, en clau ascensional -tradició espiritual en què ell s'emmarca i en què viu-, d'altra banda, amb un escatologisme ardent, de tal manera que un factor (l'apocalíptic-escatològic) potencia l'altre (la recerca d'una perfecció espiritual ascensional) mentres que açò últim tempera la vehemència del seu escatologisme, orientant-lo a una finalitat pràctica moralitzadora, de conversió, de canvi i perfecció espiritual, i mitiga així el seu caràcter terrorificant i pesimístic, que només s'usa de manera pedagògica amb vista al fi desitjat.

D'ací el caràcter eminentment pràctic de la seua espiritualitat, la qual, encara que de vegades assumeix tons d'altura especulativa que recorden la mística renano-flamenca dels seus germans d'hàbit Eckhardt, Taulero o Suso - per exemple, quan parla de la contemplació divina en el capítol 3 del seu Tractat de la vida espiritual: Així, endinsant-se en si mateix, l'home espiritual eixamplarà la pupil la de la contemplació. I per una gradació misteriosa s'elevarà fins a la contemplació angèlica i divina. En aquella contemplació s'abrasa el cor en desitjos dels béns del cel i mira tot allò terrenal com de lluny, com res. Llavors començarà a bullir en l'ànima la caritat, foc ardent que consumeix la carronya dels vicis, que plena tan completament el cor, que no deixa lloc a la vanitat» (GargantaForcada 1956: 377)-; encara que la seua doctrina espiritual de vegades assumeix alts nivells especulatius, i no obstant això, sempre va acompanyada d'una forta càrrega ascètica, que insisteix en la lluita permanent contra els vicis i la pràctica constant de les virtuts. En efecte, inclús el seu Tractat de la vida espiritual, del que està extreta la cita anterior, té un caràcter fonamentalment pràctic, perquè expressament declara a l'inici del mateix que «dicta non probo», és a dir, no utilitzarà arguments filosòfics, perquè - diu- «bumilem intendo instruere, non cum arrogantibus contentionibus deservire» (només vull ensenyar a l'humil, i no disputar amb els arrogants) (Garganta-Forcada 1956: 476), i al llarg del 
mateix Tractat posa l'èmfasi en els mitjans eficaços per a aconseguir la santedat: la pobresa, el silenci orant i la puresa de cor, als quals afig més avant l'obediència, la mortificació, l'oració litúrgica i personal, així com l'estudi, necessari per a la predicació. De manera que podem dir que l'espiritualitat vicentina és una espiritualitat per a l'acció, fortament experiencial, i mai una espiritualitat merament mental, intel lectual o especulativa, que es quede en el pla de la contemplació.

I, més en concret, la de sant Vicent és una espiritualitat per a l'acció apostòlica, evangelitzadora, com afirma en el mateix Tractat quan diu: i «aquella unió [es refereix a la unió sobrenatural amb Déu a través de Crist] et portarà a l'oblació de tu mateix; açò és, que com Crist estigues preparat a procurar la salvació dels teus germans i sol lícit per a donar la teua vida per ells, orant per ells dia i nit, treballant perquè tots visquen en Crist i Crist en ells»(Garganta-Forcada 1956: 395).

Açò obeeix a l'ambient concret en què sant Vicent Ferrer viu i en què viuen les persones a qui predica o per a qui escriu: un ambient crític, de crisi a nivell material, espiritual i eclesial, que urgeix a l'acció, o millor a la reacció, a la conversió, sobretot quan es considera pròxima, molt pròxima, la fi del món. Pot ser en altres ambients més serens l'espiritualitat de Ferrer haguera desenrotllat els aspectes místics més contemplatius, epeculatius i unitius presents en la mateixa, pot ser; encara que haguera mantingut sempre un caràcter prevalentment pràctic, perquè la personalitat de Vicent Ferrer és més donada a allò pràctic que a al vessant especulatiu. De fet, a pesar de la seua sòlida formació filosòfica i teològica, quan torna a València a finals de 1378, a banda d'impartir les classes de teologia a la catedral, veiem que Ferrer s'interessa més per les ànimes que pels llibres; no pot romandre tancat en els estrets límits de les aules escolars i comença a intervindre en la vida de la ciutat, i interferir en els assumptes públics. Prompte adquireix prestigi $\mathrm{i}$ es converteix en àrbitre dels combats nobiliaris, marmessor d'il lustres testadors, conseller indispensable dels jurats de la ciutat en tot tipus de qüestions, etc. O siga, se'ns manifesta com una personalitat humana, pràctica, oberta, realista, política (en el sentit etimològic de la paraula: interessat per la polis, per la societat), és un home d'acció, pràctic i de cap mode un fred intel lectual de gabinet, de llibre, sinó vital, d'acció.

\section{Notes característiques de l'espiritualitat vicentina}

Abans que res, com ja s'ha esmentat, és una espiritualitat inserida en el context històric del seu temps, no és una espiritualitat (un espiritualisme, caldria dir) al marge de la realitat, sinó condicionada per aquella i al servei de la mateixa, per a millorar-la i canalitzar-la al seu fi, que és Déu. És una espiritualitat encarnada en la seua època, que intenta posar remei als mals del temps, per això apareix com una espiritualitat crítica amb els vicis i pecats del clero i del poble. No podrem entendre l'espiritualitat de sant Vicent si la separem del context històric (eclesial i valencià) en què naix: el de la crisi de la seua època, però també el context dominicà en què s’insereix, propi de la seua condició de frare de l'Orde de Predicadors, perquè serà sempre la seua una espiritualitat en l'ona de 
l'espiritualitat dominicana, deutora de la seua formació teològica tomista, com s'advertix en molts passatges dels seus sermons.

La inserció en el context de la seua època té com a conseqüència que siga una espiritualitat experiencial, com opina Fagés a propòsit del Tractat valde utilis et consolatorius in tentationibus circa fidem, però que pot aplicar-se a tota la seua obra, a l'observar el domnic francés que«on y sent non seulement un esprit trés exercé aux matières spirituelles, mais surtout la lumière précise de l'expérience», perquè la seua espiritualitat brolla no sols de les seues lectures i estudis, sinó de la seua pròpia experiència conventual i social, del que viu i el que succeïx al seu voltant, i és una espiritualitat orientada a la pràctica, que intenta il luminar la vida, però al mateix temps es deixa interpel lar i qüestionar per ella. Mai és una espiritualita tmerament especulativa, intel lectual, que vaja per les altures (encara que en alguns moments, com hem dit, se’n perceben trets), sinó que aterra sempre en la existència concreta dels seus oients o lectors en busca de la perfecció espiritual amb vista a la seua salvació. Açò confereix a la seua espiritualitat un to altament incisiu, una gran utilitat, qualitats que faran que siga àmpliament divulgada inclús després de la seua mort.

D'altra banda, la inserció contextual explica que l'espiritualitat vicentina no siga gens original, en absolut, sinó que s'inspira en la tradició espiritual dominicana (concretament en sant Tomàs d'Aquino i en la Suma de virtuts de Guillem Peyrault) i en el millor de la tradició teològica i espiritual de l'Església: sant Agustí, sant Gregori el Gran, sant Bernat, sant Basili, els Pares del desert, Guillem de Saint-Thierry, Ludolf de Saxònia, i un llarg etc., com s'observa en llegir els seus sermons, on fa constant referència als Pares de l'Església i a altres teòlegs i autors espirituals. No per casualitat, a l'inici del seu Tractat de la vida espiritual confessa expressament: «Només portaré en el present tractat documents profitosos per a l'ànima i regles saludables del que ens van ensenyar i van deixar escrit els sagrats doctors», encara que adverteix que «no portaré expressament les seues paraules [...] perquè el meu interés és guardar brevetat»(Garganta-Forcada 1956: 476).

Per tant, Vicent Ferrer no pretén ser original ni aportar noves teories, sinó només ensenyar al poble, seguint la doctrina dels Sants Doctors, i en particular l'Aquinat. Inclús pel que fa al seu pensament apocalíptic, Ferrer pren molt de la tradició autòctona sobre el tema a través d'Arnau de Vilanova, les obres del qual probablement va llegir perquè s'aprecien diverses concomitàncies entre ells, així com de Joaquim de Fiore, Pere Olivi o Joan de Rocatallada, però també de sant Tomàs d'Aquino i dels dominics Venturino de Bèrgam o Robert d’Uzés; encara que, com ha mostrat Sebastián Fuster, el que pren d'ells ho fa sempre des de la seua òptica tomista, canviant termes i adaptant els posibles préstecs d'aquells autors al fi per ell perseguit: la urgència de la conversió (Fuster Perelló 2007).

Seguint en la línia esmentada de les fonts en què s'inspira l'espiritualitat vicentina, apreciem que una altra de les característiques és la seua base en la Sagrada Escriptura, la qual cosa confereix una empremta bíblica notable. En efecte, la Bíblia és «el libro básico de la predicación vicentina», perquè «de ella parte y a ella conduce toda su enseñanza» (Fuster Perelló 2007: 227). Així ho diu en un dels seus sermons, quan adverteix els seus oients que «de l'Evangeli de hui hix la vida espiritual», i encara 
que «dels altres libres de theologia havem molts refrescaments [aliments], çò és bones doctrines per a nostra vida, mas la vida principal és en lo libre de vida, çò és, en l’Evangeli» (Ferrer 1977: 25).

En efecte, l'Escriptura és el llibre guia dels seus sermons, no sols perquè la pàgina sagrada marca el tema del sermó, basat sempre en un text bíblic de la litúrgia del dia, sinó a més perquè tot el sermó està ple de cites bíbliques, que el predicador comenta adaptant-les a les necessitats dels seus oients. Fins al punt que el rector de la Universitat de París, Nicolau de Clemanges, escrivia en 1405, després d'escoltar predicar al sant: «Ningú millor que ell sap la Bíblia de memòria ni l'entén millor, ni la cita més a propòsit» (Fages1903: I, 166-167).

Açò respon també al context de la seua època, en què es va despertant entre els fidels cristians un interés creixent pel llibre sagrat; Vicent sabia que entre els seus oients cultes la lectura de la Bíblia era cada vegada major, el seu propi germà havia iniciat a finals del segle XIV una traducció de la Bíblia al valencià, i sabem que entre els llibres de la biblioteca de l'hospital dels beguins de València es trobaven diverses versions en vulgar del Nou Testament i de les epístoles de sant Pau (Rubio Vela - Rodrigo Lizondo 1992). Prova d'aquella extensió de la Bíblia en llengua vulgar és un informe inquisitorial dirigit en 1450 al cardenal-bisbe de València, Alfons de Borja, pel seu vicari general, perquè encara que és cent anys posterior al naixement de sant Vicent presenta la maduració d'un interés que s'havia despertat en temps del sant; en l'informe es deia que a la diòcesi de València hi havia moltes bíblies hebrees o traduïdes en llengua vulgar des del text hebreu, de les quals se n'havien cremat nou, perquè contenien molts errors; però el problema major era que hi havia també altres bíblies «et in magna multitudine» traduïdes a la llengua vulgar a partir de l'edició Vulgata, que estaven en mans de nobles cavallers $i$ insignes persones, $i$ concloïa afirmant que quasi totes les majors personalitats laiques del regne posseïen bíblies en romanç (Reinhardt 1981: 17).

Però eren molts els que no sabien llegir i per a ells Vicent vol explicar la Bíblia com el llibre orientador de la vida espiritual i moral del cristià, on es troben les veritats que porten a la salvació. Així ho dirà en un sermó en què compara el seu ofici de predicar amb el treball del cuiner: els cuiners - dirà- «prenen la bona vianda, llaven-la bé e coen-la bé, e donen-la amorosament. Aquest són los preÿcadors, dels quals sóc jo. E donen viandes; e quinyes? Les paraules del nostre Senyor, les doctrines que sostenen l'ànima. Axí com persona que està gran temps que no menga se enuga de endurar, axí l'ànima que no hou la paraula de Déu no ha vida. Axí ó diu Jesucrist: Non in solo pane vivit homo (Mt 4, 4)» (Ferrer 1975: 84). I ho repetirà d'una altra manera en el sermó del ric epuló i el captaire Llàtzer, en parlar de les molles de pa que cauen de la taula.

Per altra banda, sabem que Ferrer durant els seus anys de formació va estudiar hebreu i exegesi bíblica, de cara a una predicació apologètica dirigida a la conversió dels jueus; per tant, coneixia bé la Sagrada Escriptura. L'empremta bíblica determina en gran part un altre dels trets distintius de l'espiritualitat vicentina i és el seu caràcter cristocèntric, perquè està dirigida a la contemplació de la figura de Jesucrist, a fi d'imitar les seues virtuts en la vida corrent. Tot el centre de la seua espiritualitat, que apareix directament o indirectament en els seus sermons, és l'amor a Jesucrist. La 
humanitat de Crist és el primer punt que recomana meditar assíduament al lector del seu Tractat de la vida espiritual: "primera, Crist crucificat, encarnat, amb els altres passos de la seua vida i passió». I insisteix: «Coses ha de contemplar dia i nit, a saber, el feliç estat dels què res pensen ni parlen, ni agraden sinó només a Jesucrist i, aquell, crucificat»(Garganta-Forcada 1956: 540).

Aquella contemplació amorosa de Crist, és a dir, el fet de prendre Crist com a punt de referència en tot, ha de portar a la cristificació de la vida, a la conformació amb Crist, que és el que sant Vicent pretén: que els seus oients visquen com va viure Crist, tal com recomanava al deixeble per a qui va escriure el seu Tractat de la vida espiritual: És convenient que «desconfiant totalment de tu mateix, de les teues bones obres i de tota la teua vida, et convertisques totalment i t'abandones en els braços de Jesucrist mort per tu [...], de manera que arribes tu també a ser mort en totes les teues sensualitats humanes i Jesucrist crucificat visca en el teu cor i en la teua ànima. I així, totalment transformat i transfigurat el teu cor, mai veges ni sentes sinó a Crist mort i pendent en la creu per tu, a exemple de la Mare de Déu, perquè sigues mort al món i viu en la fe» (Garganta-Forcada 1956: 532).

La mateixa finalitat es percep en el seu tractat Contemplació molt devota de la vida de Jesucrist, on dirà que «Crist és la font de totes les gràciesespirituals», al que tot cristià ha d'estar unit a través de l'oració, l'obediència i la penitència, i tota la seua vida s'ha «d'adreçar i reduir a Crist». Així, centrada en la contemplació de la humanitat de Crist, l'espiritualitat vicentina adquirix un to afectiu, càlid, allunyat de l'intel lectualisme fred i de la vana especulació de la mística escolàstica, afectivitat que tempera les asprors pròpies del seu «escatologisme», encara que de vegades se n’impose el to més dur i incisiu. Així ho recomanava al destinatari del seu Tractat de la vida espiritual: «En les predicacions i sermons usa un llenguatge senzill i una manera de parlar familian». I prosseguia: «Insistix amb exemples, perquè tot pecador que tinga aquell pecat, es senta al ludit, com si per a ell només predicares». I concloïa: «Però parla de tal manera que les teues paraules apareguen sempre com a eixides no d'un pit superb o indignat sinó d'unes entranyes plenes de caritat i d'amor paternal, a la manera d'un pare que es dol de veure pecar als seusfills [...] o caiguts en una profunda foia i s'esforça a traure'ls d'allí» (Garganta-Forcada 1956: 513). Era el que ell mateix feia en les seues predicacions.

Perquè l'espiritualitat vicentina és una espiritualitat oberta, d'amplis horitzons, en el sentit de no estar restringida als clergues, als religiosos o als eclesiàstics, sinó que busca arribar i ser útil també als seglars, als laics, a tot el cos cristià, la reforma i conversió del qual pretén.

Tot amb tot, es podrien afegir molts més aspectes, però baste el que s'ha esmentat en aquestes pàgines per a comprendre que l'espiritualitat de sant Vicent Ferrer, condicionada pel context crític de la seua època i per la seua vocació dominicana, va ser abans que res una espiritualitat apostòlica, dirigida fonamentalment a la comprensió i vivència de l'Evangeli. 
Miguel Navarro Sorní. L'espiritualitat de sant Vicent Ferrer en el context de la seua època

\section{Bibliografia}

Baloup, Daniel (2008) «Sainteté et modèles de vie dans la prédication castillane de Vincent Ferrer», en S. Cassagnes-Brouquet - A. Dubreil-Arcin (ed.), Le Ciel sur cette terre. Dévotions, Église et religión au Moyen Âge. Mélanges en l'honneur de Michelle Fournié, Toulouse, CNRS-Université Toulouse-Le Mirail, pp. 81-89.

Eiximenis, Francesc (1983) El crestià. (Selecció), a cura d'Albert Hauf, Barcelona, Edicions 62.

Esponera Cerdán, Alfonso (2007) El oficio de predicar. Los postulados teológicos de los sermones de San Vicente Ferrer, Salamanca, San Esteban.

Fages, Henry (1903) Historia de san Vicente Ferrer, Valencia, Agapito García editor.

Ferrer, Sant Vicent (1975) Sermons, volum III, a cura de Gret Schib, Barcelona, Barcino.

- (1977) Sermons, volum IV, a cura de Gret Schib, Barcelona, Barcino.

Fuster Perelló, Sebastián (2007) «Rasgos milenaristas en la tradición dominicana y en san Vicente Ferrer», en E. Callado (ed.), El fuego y la palabra. San Vicente Ferrer en el 550 aniversario de su canonización, Actas del 1 er Simposium Internacional Vicentino.Valencia, 26 - 29 de abril de 2005, Valencia, Generalitat Valenciana, pp. 207-232.

Garganta, José María de - Forcada, Vicente (1956) Biografía y escritos de San Vicente Ferrer, Madrid, BAC.

Huizinga, Johan (1971) El otoño de la Edad Media. Estudio sobre las formas de la vida y del espíritu durante los siglos XIV y XV en Francia y en los Países Bajos, Madrid, Revista de Occidente.

Leppin, Volker (2010) «La spiritualità nel tardo Medioevo», en Th. Kaufmann - R. Kottje (eds.), Storia ecuménica della Chiesa, vol. 2: Dal basso Medioevo alla prima età moderna, Brescia, Queriniana, pp. 220-247.

Losada, Carolina M. (2019) «Vicent Ferrer, misionero apocalíptico. Sobre el uso de la pedagogía del terror en sus sermones medievales hispanos», Anuario de estudios medievales 49, pp. 189-213.

Mezzadri, Luigi (2001) Storia della Chiesa tra Medioevo ed època moderna, vol. 1: Dalla crisi della Cristianità alle Riforme (1294-1492), Roma, Edizioni Centro Liturgico Vincenziano.

Reinhardt, Klaus (1981) «Hebräische und spanische Bibeln auf dem Scheiterhaufen der Inquisition», en Historisches Jabrbuch im Auftrag der Görres-Gesellschaft 101, pp. 1-37.

Rubio Vela, Austín - Rodrigo Lizondo, Mateu (1992) «Els beguins de València en el segle XIV. La seua casa-hospital i els seus llibres», en A, Ferrando Francés (coord..), Miscel tània Sanchis Guarner III, València, pp. 185-228.

Vandenbroucke, François (1961) «Descrédit de la mystique spéculative et de la vie conventuelle», en J. Leclercq - F. Vandenbroucke - L. Bouyer, La spiritualité du Moyen Age, París, Aubier, pp. 487-489. 